Research article

Open Access

\title{
Development and Characterization of New Indomethacin Self-Nanoemulsifying Formulations
}

\author{
Ehab I. TAHA ${ }^{1,2}$ \\ ${ }^{1}$ Department of Pharmaceutics, Faculty of Pharmacy, King Saud University, Riyadh, Saudi Arabia. \\ ${ }^{2}$ Department of Pharmaceutics and Industrial Pharmacy, Faculty of Pharmacy, Al-Azhar University, Nasr \\ City, Cairo, Egypt. \\ E-mails: ehab71328@yahoo.com or eelbadawi@ksu.edu.sa \\ Sci Pharm. 2009; 77: 443-451 \\ doi:10.3797/scipharm.0811-24 \\ Published: March $14^{\text {th }} 2009 \quad$ Received: November $26^{\text {th }} 2008$ \\ Accepted: $\quad$ March $12^{\text {th }} 2009$ \\ This article is available from: http://dx.doi.org/10.3797/scipharm.0811-24 \\ (C) Taha; licensee Österreichische Apotheker-Verlagsgesellschaft m. b. H., Vienna, Austria. \\ This is an Open Access article distributed under the terms of the Creative Commons Attribution License \\ (http://creativecommons.org/licenses/by/3.0/), which permits unrestricted use, distribution, and reproduction \\ in any medium, provided the original work is properly cited.
}

\begin{abstract}
In the present work a new indomethacin (IND) self-nanoemulsifying drug delivery formulation (SNEDDF) have been prepared to enhance its dissolution which in turn could provide a better chance for IND oral absorption. IND SNEDDF have been prepared using different concentrations of castor oil as a solvent for IND, Cremophor RH $40(\mathrm{Cr}-40)$ as surfactant and Capmul MCM-C8 (Ca-8) as co-surfactant. Droplets size and turbidity of IND SNEDDFs were measured. Dissolution profile of IND SNEDDFs filled in gelatin capsules was determined by using USP apparatus 2 . Ternary phase diagram was constructed to identify the self-nanoemulsifying region after evaluation of IND SNEDDFs by the visual observation. The IND SNEDDFs were thermally characterized using differential scanning calorimetry (DSC) to ensure the compatibility among its ingredients. The present study revealed that the SNEDDFs increased IND dissolution rate and has the potential to enhance its bioavailability without interaction or incompatibility between the ingredients.
\end{abstract}

\section{Keywords}

Indomethacin • Nanoemulsion • DSC $\cdot$ SNEDDF • Dissolution

\section{Introduction}

IND is a lipophilic non-steroidal anti-iflammatory drug commonly used to reduce fever, pain, stiffness, and swelling [1]. It is the drug of choice for the closure of a patent ductus 
arteriosus in neonates by virtue of its vasoconstrictive action in the tissues of the ductus [2]. Because IND inhibits both $\operatorname{COX} 1$ and $\operatorname{COX} 2$, it inhibits the production of prostaglandins in the stomach and intestine which maintain the mucous lining of the gastrointestinal tract [3], therefore, like other nonselective COX inhibitors, IND may cause peptic ulcers [4]. The ulcers may result in serious bleeding and/or perforation which requiring hospitalization of the patient, some even die from these complications [5]. IND is extensively bound to plasma proteins, and has wide inter-subject variability in the plasma concentrations, half life and therapeutic response in premature neonates [2]. SEDDFs are isotropic mixtures of natural or synthetic oil, surfactant(s) with or without a co-surfactant. Upon mild agitation these systems can form fine oil in water emulsions in aqueous media, such as dissolution media or gastrointestinal fluids, [6]. Self-emulsifying formulations spread readily in such aqueous media providing the drug in nanometer droplets size which in turn enhance the dissolution rate of lipophilic drugs by increasing their aqueous solubility. However, studies have shown that the self-emulsification process is specific to the nature of the oil/surfactant pair, surfactant concentration, oil/surfactant ratio and temperature at which self-emulsification occurs $[7,8]$. The present study is a trial to formulate IND in a SNEDDF to increase its solubility in water and hence improving its dissolution rate which in turn may enhance IND oral bioavailability.

\section{Materials and methods}

\section{Chemicals:}

IND, and castor oil were purchased from Sigma Chemical Co. (St. Louis, Mo., USA). Macrogol-glycerol hydroxystearate $(\mathrm{Cr}-40)$ was obtained from BASF Corp. (Mount Olive. N.J., USA). Glyceryl monocaprylate (Ca-8) was obtained from Abitec Corp. (Jamesville, Wisc., USA). Hard gelatin capsules were supplied by Shionogi Qualicaps (Whitest, N.C., USA). All chemicals were used as received.

\section{Preparation of IND SNEDDFs:}

A series of IND SNEDDFs were prepared with fixed concentration of IND $(25 \mathrm{mg})$ and varying concentrations of castor oil, $\mathrm{Cr}-40$ and $\mathrm{Ca}-8$. IND was dissolved in the amount of castor oil and then $\mathrm{Cr}-40$ and $\mathrm{Ca}-8$ were accurately weighed and added to IND oily solution. The mixture was mixed using magnetic stirrer until a clear solution was obtained. An exact amount of each formulation equivalent to $25 \mathrm{mg}$ IND was filled into hard gelatin capsules. The filled capsules were stored in a refrigerator until their use in subsequent studies. Table 1 shows all the formulations composition.

\section{In vitro characterization of IND SNEDDF}

\section{Visual observations:}

From each formulation, $1025 \mathrm{mg}$ was introduced into $50 \mathrm{ml}$ of water in a glass Erlenmeyer flask at $25{ }^{\circ} \mathrm{C}$ and the contents were gently agitated manually. The tendency to spontaneously form a transparent emulsion was judged as good and it was judged bad when there was poor or no emulsion formation $[9,10]$. Phase diagram was constructed identifying the good self-emulsifying region. All studies were repeated in triplicates and the mean values are shown in Figure 1. 
Tab. 1. IND SNEDDFs composition.

\begin{tabular}{|c|c|c|c|c|}
\hline $\begin{array}{l}\text { Formulation } \\
\text { No. }\end{array}$ & $\begin{array}{l}\text { IND } \\
(\mathrm{mg})\end{array}$ & $\begin{array}{l}\text { Castor oil } \\
\text { (mg) }\end{array}$ & $\begin{array}{l}\text { Cr- } 40 \\
(\mathrm{mg})\end{array}$ & $\begin{array}{l}\text { Ca-8 } \\
\text { (mg) }\end{array}$ \\
\hline 1 & 25 & 100 & 800 & 100 \\
\hline 2 & 25 & 100 & 700 & 200 \\
\hline 3 & 25 & 100 & 600 & 300 \\
\hline 4 & 25 & 100 & 500 & 400 \\
\hline 5 & 25 & 100 & 400 & 500 \\
\hline 6 & 25 & 100 & 300 & 600 \\
\hline 7 & 25 & 100 & 200 & 700 \\
\hline 8 & 25 & 100 & 100 & 800 \\
\hline 9 & 25 & 200 & 700 & 100 \\
\hline 10 & 25 & 200 & 600 & 200 \\
\hline 11 & 25 & 200 & 500 & 300 \\
\hline 12 & 25 & 200 & 400 & 400 \\
\hline 13 & 25 & 200 & 300 & 500 \\
\hline 14 & 25 & 200 & 200 & 600 \\
\hline 15 & 25 & 200 & 100 & 700 \\
\hline 16 & 25 & 300 & 600 & 100 \\
\hline 17 & 25 & 300 & 500 & 200 \\
\hline 18 & 25 & 300 & 400 & 300 \\
\hline 19 & 25 & 300 & 300 & 400 \\
\hline 20 & 25 & 300 & 200 & 500 \\
\hline 21 & 25 & 300 & 100 & 600 \\
\hline 22 & 25 & 400 & 500 & 100 \\
\hline 23 & 25 & 400 & 400 & 200 \\
\hline 24 & 25 & 400 & 300 & 300 \\
\hline 25 & 25 & 400 & 200 & 400 \\
\hline 26 & 25 & 400 & 100 & 500 \\
\hline 27 & 25 & 500 & 400 & 100 \\
\hline 28 & 25 & 500 & 300 & 200 \\
\hline 29 & 25 & 500 & 200 & 300 \\
\hline 30 & 25 & 500 & 100 & 400 \\
\hline
\end{tabular}

\section{Turbidity measurements:}

From each formulation, $1025 \mathrm{mg}$ was introduced into $50 \mathrm{ml}$ of water at $25{ }^{\circ} \mathrm{C}$ and the contents were gently stirred manually. Turbidity of the resultant emulsions given in nephrometric turbidity unit (NTU) was measured using Orbeco-Hellige model 966, Orbico Analytical System Inc., Farming dale, NY, USA. All measurements were done in triplicate.

\section{Emulsion droplets size analysis:}

From each formulation, $1025 \mathrm{mg}$ was introduced into $50 \mathrm{ml}$ of water at $25{ }^{\circ} \mathrm{C}$ and the contents were gently stirred manually. The mean droplets size distribution of the resultant emulsion was determined by laser diffraction analysis (NiComp Particle Size system ZW380 Version 2 Santa Barbara, California, USA). The sizing of the emulsion was determined in a small volume module. Samples were directly placed into the module and 
the data were collected for $15 \mathrm{~min}$. Droplets size was calculated from the volume size distribution. All measurements were done in triplicate.

\section{Dissolution study:}

Dissolution of IND SNEDDFs filled in hard gelatin capsules was determined using USP24 rotating paddle apparatus (VK7000, vankel, USA) at $37 \pm 0.5{ }^{\circ} \mathrm{C}$ and a rotating speed of $50 \mathrm{rpm}$ in $900 \mathrm{ml}$ of water. Capsules were held to the bottom of the vessel using copper sinkers. A sample $(3 \mathrm{ml})$ withdrawn after 30 minutes was filtered using a $10 \mu \mathrm{m}$ VanKel filter and assayed for IND using spectrophotometric method at $320 \mathrm{~nm}$ [11]. The dissolution experiment was carried out in triplicates.

Tab. 2. Physical parameters for IND SNEDDFs.

\begin{tabular}{|c|c|c|c|c|}
\hline $\begin{array}{l}\text { Formulation } \\
\text { No. }\end{array}$ & $\begin{array}{l}\text { Visual } \\
\text { observation }\end{array}$ & $\begin{array}{l}\text { Mean turbidity } \\
\text { (NTU) }\end{array}$ & $\begin{array}{l}\text { Mean droplets } \\
\text { size }(\mathrm{nm})\end{array}$ & $\begin{array}{l}\% \\
\text { Release }\end{array}$ \\
\hline 1 & Bad & $-{ }^{*}$ & - & - \\
\hline 2 & Bad & - & - & - \\
\hline 3 & Bad & - & - & - \\
\hline 4 & Good & 34 & $174 \pm 4.51$ & 70 \\
\hline 5 & Good & 14 & $112 \pm 8.33$ & 78 \\
\hline 6 & Good & 5.4 & $72 \pm 3.51$ & 82 \\
\hline 7 & Good & 3.7 & $54 \pm 4.51$ & 87 \\
\hline 8 & Good & 1.2 & $30 \pm 4.04$ & 93 \\
\hline 9 & Bad & - & - & - \\
\hline 10 & Bad & - & - & - \\
\hline 11 & Good & 103 & $396 \pm 7.51$ & 59 \\
\hline 12 & Good & 77 & $262 \pm 8.31$ & 64 \\
\hline 13 & Good & 31 & $158 \pm 5.86$ & 72 \\
\hline 14 & Good & 24 & $131 \pm 3.06$ & 74 \\
\hline 15 & Good & 16 & $120 \pm 4.04$ & 78 \\
\hline 16 & Bad & - & - & - \\
\hline 17 & $\mathrm{Bad}$ & - & - & - \\
\hline 18 & Bad & - & - & - \\
\hline 19 & Bad & - & - & - \\
\hline 20 & Good & 102 & $379 \pm 5.03$ & 67 \\
\hline 21 & Good & 84 & $291 \pm 7.00$ & 61 \\
\hline 22 & Bad & - & - & - \\
\hline 23 & Bad & - & - & - \\
\hline 24 & Bad & - & - & - \\
\hline 25 & Bad & - & - & - \\
\hline 26 & Good & 109 & $411 \pm 8.08$ & 55 \\
\hline 27 & Bad & - & - & - \\
\hline 28 & Bad & - & - & - \\
\hline 29 & Bad & - & - & - \\
\hline 30 & Bad & - & - & - \\
\hline
\end{tabular}




\section{Differential scanning Calorimetry:}

Samples of IND alone and its physical mixture with additives (castor oil, Cr-40, and Ca-8) in a ratio of 1:1 were accurately weighed, encapsulated and hermetically sealed in flat bottomed aluminum pan with crimped on lid. The pans were positioned on sample pan holder of a Perkin-Elmer DSC7. The samples were heated in an atmosphere of nitrogen over a temperature range from 30 to $250^{\circ} \mathrm{C}$ with a constant heating rate of $10{ }^{\circ} \mathrm{C} / \mathrm{min}$. Thermograms were obtained by the DSC7 thermal analyzer program and recorded at constant chart speed of $1 \mathrm{in} . / \mathrm{min}$. The thermogram, transition temperature range, the onset of peak transition and the maximum peak of transition were recorded using Okidata Microline 320 and 9 Pin Printer. Two replicates were made for each DSC thermogram using an empty sealed aluminum pan as reference and indium as instrument calibration standard.

\section{Results and Discussion}

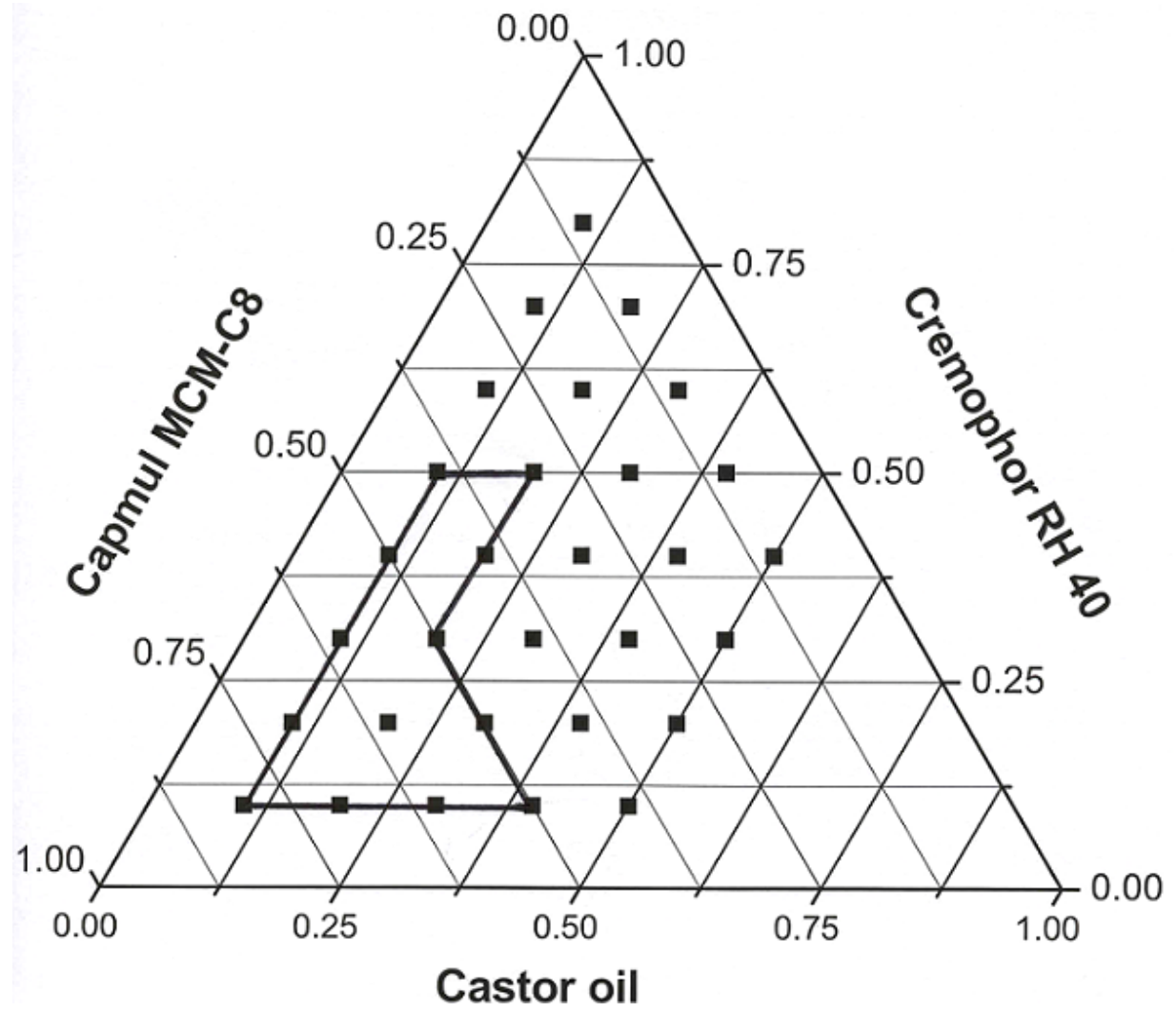

Fig. 1. Ternary phase diagram shows the efficient self-emulsification region.

\section{Visual observations:}

For the preparing of a SNEDDF, an appropriate mixture of surfactants should be used to produce a stable microemulsion having droplet size in nanometer range $[9,12]$. In this study, $\mathrm{Cr}-40$ with an average HLB value of 12 and Ca- 8 with an average HLB value of 3.5 were selected. Spontaneity of emulsions formation was evaluated and a ternary phase diagram of the system comprising the $\mathrm{Cr}-40, \mathrm{Ca}-8$ and castor oil was constructed 
(Figure 1). All the components were converted to percent weight per weight before constructing the ternary phase diagram. The area enclosed within the solid line represents the region of self-emulsification. The area enclosed within the solid line in the ternary phase diagram of IND SNEDDF is different from that obtained with retinol acetate SNEDDF [8] which may be due to the different physicochemical properties of IND. Within this area the prepared formulations form fine oil in water emulsion with gentle agitation. The mechanism of emulsions formation could be explained as follow: $\mathrm{Cr}-40$, due to its water solubility, localized on the surface of the castor oil droplets reducing the interfacial free energy between castor oil and the water so it provides a mechanical barrier to prevent oil droplets from coalescence resulting in a thermomechanically stable emulsion [13]. Cr-8 was used to provide more stabilization for castor oil droplets and solubilization to IND [14]. Furthermore, owing to its crystallization inhibition property, Ca-8 prevent the crystallization of IND in formulation and emulsion which provide stability and efficacy for the formulations as it was indicated from DSC study.

\section{Turbidity:}

Turbidity values have been reported to be of use in SNEDDS characterization [10], therefore it was performed on IND SNEDDFs which have passed the visual observation test (marked good). In the turbidity measurement, the amount of scattered light (when an incident light is subjected to strike small particles) is measured and used in turbidity calculations as per the Rayleigh's theory [15]. Light scattering by colloids conforms to Raleigh theory, which predicts that light scattering or measured turbidity ( $r$ ) in a simplified equation can be given by $r=K_{n v}^{2}$ in which $\mathrm{K}$ is a machine constant, $v$ is particle volume and $\mathrm{n}$ is the number of particles [15]. The turbidity measurements may be reasonable compromise when dissolution of a drug from SNEDDFs can not be measured because of low solubility of drug. Table 2 shows a good correlation between the visual observation and turbidity of all formulations. Regarding the relation between turbidity of IND SNEDDFs and castor oil, $\mathrm{Cr}-40$ and $\mathrm{Ca}-8$ concentrations, it is obvious that $\mathrm{Ca}-8$ concentration have a great influence on the turbidity of IND SNEDDFs.

\section{Emulsion droplet size analysis:}

Nanoemulsions are characterized by the droplets size of nanometer range. Therefore droplets size analysis was performed on IND SNEDDFs which have passed the visual observation test (marked good) to see whether the resultant emulsions are indeed nanoemulsions. As seen in Table 2, all the droplets size of the prepared SNEDDFs which marked good in visual observation test are in nanometer size range. A careful observation in Table 2 shows that the amount of IND dissolved in 30 min ( $t_{30}$ values) increases when the droplets size decreases. It is clear that increasing the concentration of Ca-8 lead to decreasing droplets size.

\section{Dissolution study:}

The release of IND from selected SNEDDFs (marked good) was markedly different from one formulation to another depending on the ratio of castor oil, $\mathrm{Cr}-40$ and $\mathrm{Ca}-8$ in each formulation. It is obvious that any change in the droplets size and/or the turbidity of the prepared formulations is reflecting dramatically on the dissolution rate of IND. In another words there is an inversely relationship between droplets size of the formulations and its drug release percent. Both castor oil and Ca-8 concentrations have a great impact on IND 
release from SNEDDFs. From the data of the dissolution study it is clear that the optimum ratio for $\mathrm{Cr}-40$ to $\mathrm{Ca}-8$ is $1: 8$ that is obvious in formulation number 8 , which gave the lowest droplet size $(30 \mathrm{~nm})$ and in turn has the highest amount of drug release $(93 \%)$ in 30 minutes. Also, from Table 1 and 2 it is clear that changing the 1:8 Cr-40 to Ca-8 ratio to higher amount of $\mathrm{Cr}-40$ and low amount of $\mathrm{Ca}-8$ led to increasing the droplets size of the formulations and hence decreasing the dissolution of IND from the formulations.

\section{Differential scanning calorimerty:}

The DSC thermogram of IND (Fig. 2, A) shows a characteristic endothermic peak at $154{ }^{\circ} \mathrm{C}$ due to its melting. From Figure 2 it is clear that the physical mixture of IND and the components of SNEDDF ingredients at a ratio of $1: 1$ indicates the presence of small endothermic peak of IND with reduction of intensity and shifting to lower temperature. Moreover, (Fig. 2, E) IND SNEDDF thermogram shows more reduction in size and intensity of the endothermic peak of the drug which may be due to its solubility in the nanoemulsuion ingredients. These data agree with data of mean droplets size (Table 2) where decreasing size of the drug particles led to decrease in crystallinity and shifting of melting peak to lower temperature degree.

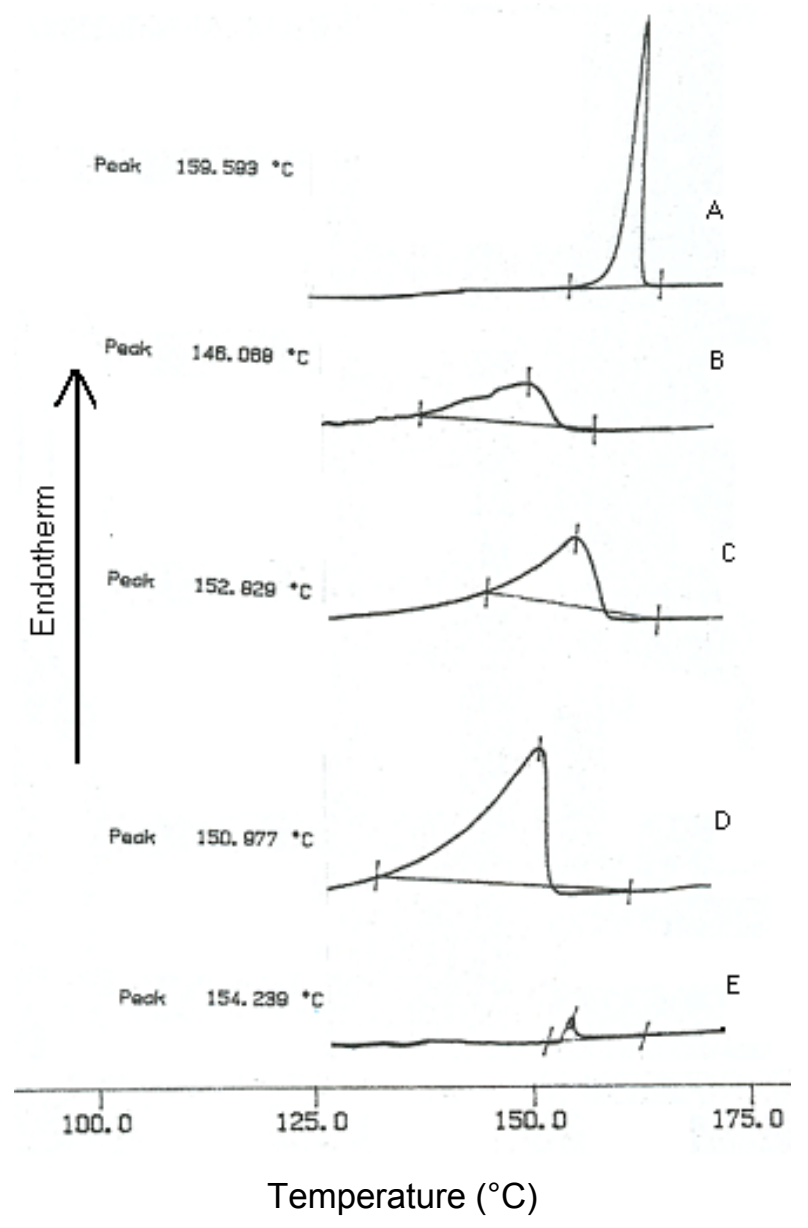

Fig. 2. DSC thermograms of IND (A), IND and castor oil mixture (B), IND and Cr-40 mixture (C), IND and Ca-8 mixture (D) and IND SNEDDF (E). 


\section{Conclusion}

The results obtained from this study revealed that by using the proper ratio and kind of oil, surfactant and co-surfactant, IND can be easily formulated into a SNEDDF with desired particle size range, turbidity and the amount of drug released. Formulation 8 which contains castor oil, Cr-40 and Ca-8 in a ratio of 1:1:8 characterized by having the lowest turbidity and droplets size values (1.2 NTU and $30 \mathrm{~nm}$, respectively) and the highest amount of drug release after 30 minutes (93\%).

\section{Author's Statement(s)}

\section{Competing Interests}

The author declares no conflict of interest.

\section{References}

[1] Inoue K, Fujisawa H, Motonaga A, Inoue Y, Kyoi T, Ueda F,Kimura K.

Anti-inflammatory effects of etodolac: comparison with other non-steroidal anti-inflammatory drugs.

Biol Pharm Bull. 1994; 17: 1577-1583.

PMid:7735198

[2] Al Za'abi MA, Dehghanzadeh GH, Norris RL, Charles BG.

A rapid and sensitive microscale HPLC method for the determination of indomethacin in plasma of premature neonates with patent ductus arteriousus.

J Chromatogr B Analyt Technol Biomed Life Sci. 2006; 830: 364-367.

doi:10.1016/j.jchromb.2005.11.025

[3] Yokota A, Taniguchi M, Tanaka A, Takeuchi K.

Development of intestinal, but not gastric damage caused by a low dose of indomethacin in the presence of rofecoxib.

Inflammopharmacology. 2005; 13: 209-216.

doi:10.1163/156856005774423755

[4] Dengiz GO, Odabasoglu F, Halici Z, Suleyman H, Cadirci E, Bayir Y.

Gastroprotective and antioxidant effects of amiodarone on indomethacin induced gastric ulcers in rats. Arch Pharm Res. 2007; 30: 1426-1434.

doi:10.1007/BF02977367

[5] Risty GM, Najarian MM, Shapiro SB.

Multiple indomethacin induced jejunal ulcerations with perforation: a case report with histology.

Am Surg. 2007; 73: 344-6.

PMid:17439025

[6] Charman SA, Charman WN, Rogge MC, Wilson TD, Dutko PJ, Pouton CW.

Self-emulsifying drug delivery systems: formulation and biopharmaceutic evaluation of an investigational lipophilic compound.

Pharm Res. 1992; 9: 87-93.

doi:10.1023/A:1018987928936

[7] Gershanik T, Benita S.

Self-dispersing lipid formulations for improving oral absorption of lipophilic drugs.

Eur J Pharm Biopharm. 2000; 50: 179-188.

doi:10.1016/S0939-6411(00)00089-8 
[8] Taha El, Al-Saidan S, Samy AM, Khan MA.

Preparation and in vitro characterization of self-nanoemulsified drug delivery system (SNEDDS) of alltrans-retinol acetate.

Int J Pharm. 2004; 285: 109-119.

doi:10.1016/j.ijpharm.2004.03.034

[9] Craig DQ, Barker SA, Banning D, Booth SW.

An investigation into the mechanism of self-emulsification using particle size analysis and low frequency dielectric spectroscopy.

Int J Pharm. 1995. 114: 103-110.

doi:10.1016/0378-5173(94)00222-Q

[10] Nazzal S, Smalyukh II, Lavrentovich OD, Mansoor AK.

Preparation and in vitro characterization of a eutectic based semisolid self-nanoemulsified drug delivery system (SNEDDS) of ubiquinone: mechanism and progress of emulsion formulation.

Int J Pharm. 2002; 235: 247-265.

doi:10.1016/S0378-5173(02)00003-0

[11] Gong K, Darr JA, Rehman IU.

Supercritical fluid assisted impregnation of indomethacin into chitosan thermosets for controlled release applications.

Int J Pharm. 2006; 315: 93-98.

doi:10.1016/j.ijpharm.2006.02.030

[12] Pouton CW.

Lipid formulations for oral administration of drug non-emulsifying, self-emulsifying and self-microemulsifying drug delivery system.

Eur J Pharm Sci. 2000; 11 (Suppl 2), S93-S98.

doi:10.1016/S0928-0987(00)00167-6

[13] Reiss $\mathrm{H}$.

Entropy-induced dispersion of bulk liquids.

J Colloid Interface Sci. 1975; 53: 61-70.

doi:10.1016/0021-9797(75)90035-1

[14] Constantinides PP, Scalart JP.

Formulation and physical characterisation of water in oil microemulsions containing long versus medium chain length glycerides.

Int J Pharm. 1997; 158: 57-68.

doi:10.1016/S0378-5173(97)00248-2

[15] Pouton CW.

Self-emulsifying drug delivery systems. Assessment of the efficiency of emulsification.

Int J Pharm. 1985; 27: 335-348.

doi:10.1016/0378-5173(85)90081-X 